\title{
Role of Antimicrobial Selective Pressure and Secondary Factors on Antimicrobial Resistance Prevalence in Escherichia coli from Food-Producing Animals in Japan
}

\author{
Kazuki Harada ${ }^{1,2}$ and Tetsuo Asai ${ }^{1}$ \\ ${ }^{1}$ National Veterinary Assay Laboratory, Ministry of Agriculture, Forestry and Fisheries, 1-15-1 Tokura, \\ Kokubunji, Tokyo 185-8511, Japan \\ ${ }^{2}$ Department of Veterinary Microbiology, Nippon Veterinary and Life Science University, 1-7-1 Kyonan, \\ Musashino, Tokyo 180-8602, Japan \\ Correspondence should be addressed to Tetsuo Asai, asai-t@nval.maff.go.jp \\ Received 8 December 2009; Accepted 16 March 2010 \\ Academic Editor: John E. Degener
}

Copyright (C) 2010 K. Harada and T. Asai. This is an open access article distributed under the Creative Commons Attribution License, which permits unrestricted use, distribution, and reproduction in any medium, provided the original work is properly cited.

The use of antimicrobial agents in the veterinary field affects the emergence, prevalence, and dissemination of antimicrobial resistance in bacteria isolated from food-producing animals. To control the emergence, prevalence, and dissemination of antimicrobial resistance, it is necessary to implement appropriate actions based on scientific evidence. In Japan, the Japanese Veterinary Antimicrobial Resistance Monitoring System (JVARM) was established in 1999 to monitor the antimicrobial susceptibility of foodborne and commensal bacteria from food-producing animals. The JVARM showed that the emergence and prevalence of resistant Escherichia coli were likely linked to the therapeutic antimicrobial use in food-producing animals through not only direct selection of the corresponding resistance but also indirect selections via cross-resistance and coresistance. In addition, relevant factors such as host animals and bacterial properties might affect the occurrence and prevalence of antimicrobialresistant E. coli under the selective pressure from antimicrobial usage. This paper reviews the trends in antimicrobial resistance in E. coli and consumption of antimicrobials agents in Japan and introduces the relationship between antimicrobial usage and prevalence of antimicrobial-resistant bacteria, from food-producing animals under the JVARM program. In this paper, we will provide the underlying information about the significant factors that can help control antimicrobial resistance in bacteria in veterinary medicine.

\section{Introduction}

Antimicrobial agents are essential for the prevention, control, and treatment of bacterial infections in animals and are also still used for growth promotion in animal husbandry in many countries $[1,2]$. The use of antimicrobial agents, however, can cause the emergence, prevalence, and dissemination of antimicrobial resistance in bacteria. The effect on human health has been a concern since Swann et al. reported that antimicrobial-resistant bacteria, arising from the use of veterinary antimicrobial agents, were transmitted to humans through livestock products and reduced the efficacy of antimicrobial drugs in humans [3]. The development of antimicrobial resistance in bacteria of animal origin reduces the efficacy of veterinary antimicrobial drugs $[1,4]$. Thus far, these issues have been addressed by relevant international organizations including the Food and Agriculture Organization (FAO), International Committee of Office International des Epizooties (OIE), World Health Organization (WHO), and Codex, as described elsewhere $[5,6]$.

In response to the establishment of OIE international standards [7] and FAO/OIE/WHO recommendations [8, 9], monitoring systems for antimicrobial resistance in bacteria isolated from food-producing animals were created in several countries. In Japan, the Japanese Veterinary Antimicrobial Resistance Monitoring System (JVARM) was established in 
1999 to study trends in resistance and associations between usage of antimicrobial agents and resistance and to provide data for risk assessment and management [10]. The JVARM is based on three categories of bacteria-animal pathogens, which are in general derived from diseased animals, and zoonotic and commensal bacteria, which are derived from fecal samples of apparently healthy animals.

Trends in antimicrobial resistance in bacteria are closely related to the use of antimicrobial agents in veterinary medicine $[1,4]$. In reality, however, there are several factors that participate in the association between the usage of antimicrobials and the presence of antimicrobial resistance. The factors affecting the occurrence, prevalence, and dissemination of resistance should be identified in each country to implement appropriate actions to limit the emergence, prevalence, and dissemination of antimicrobial resistance and the improvement of human and animal health. The present paper outlines the trend in antimicrobial resistance in $E$. coli in Japan. In addition, it also reviews the significant factors that can influence the prevalence of antimicrobial resistance in bacteria, mainly E. coli isolates from foodproducing animals under the JVARM program.

\section{Veterinary Use of Antimicrobial Agents and Antimicrobial Resistance in Commensal E. coli Isolated from Food-Producing Animals in Japan}

2.1. The Usage Volume of Veterinary Antimicrobial Drugs and Feed Additives. In Japan, antimicrobial agents in foodproducing animals have been used as (1) veterinary medical products for treating an animal, or group of animals that exhibit(s) evident clinical disease, and (2) feed additives for growing animals by improving their physiological performance $[11,12]$. Under the laws and regulations, the former products are either administered or sold to the end user by veterinary practitioners, or purchased by farmers/animal owners according to veterinary prescription, whereas the latter products premixed with animal feedstuff are purchased by farmers/animal owners from animal feed companies.

The usage volumes of antimicrobial drugs and feed additives have been separately calculated in Japan. The use of veterinary antimicrobial drugs was started in 1960s. Since 2000, pharmaceutical companies that produce and/or import antimicrobials for animals are required to submit data on the annual sales volume (weight of active compound) by substance, class, and animal species, under the Pharmaceutical Affairs Law.

The sales volume of veterinary medical products from 2000 to 2005 is shown in Figure 1. The total antimicrobial consumption of animals increased temporarily from 2000 (970 tons) to 2001 (1060 tons) and since then decreased to 870 tons in 2005 . Tetracyclines remained the most commonly used antimicrobials in the veterinary field (average of 417 tons), followed by sulfonamides (145 tons), macrolides (103 tons), penicillins (92 tons), aminoglycosides (62 tons), and phenicols (23 tons). These consumptions tend to be greater in pigs and poultry, and lesser in cattle. On the other

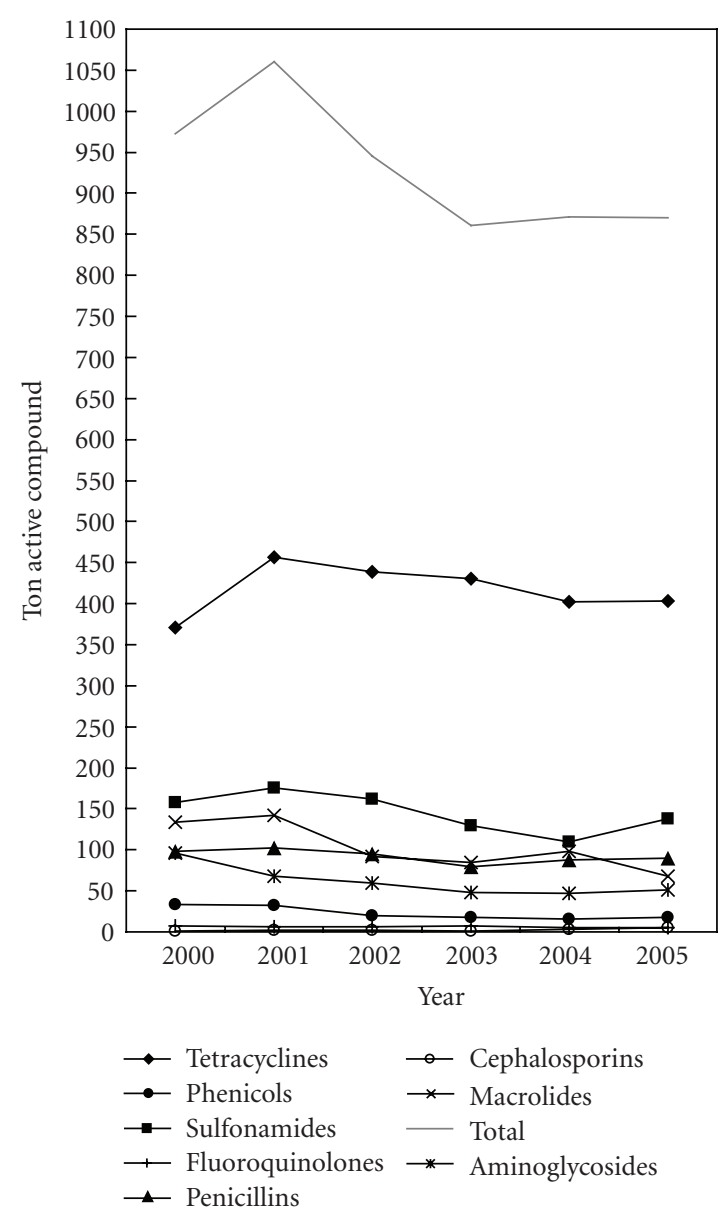

FIGURE 1: Trends in veterinary antimicrobials sold from pharmacies in Japan.

hand, the consumption volume of fluoroquinolones and cephalosporins, which are regarded as critically important antimicrobials in human medicine [13], was estimated to be smaller (average of 6.5 and 2.4 tons, resp.). An estimated 54\% of the total antimicrobial consumption by animal species has been used for pigs, followed by poultry, and cattle (approximately 16\% and 8\%, resp.) [11].

The use of antimicrobial feed additives was started in 1950s. In Japan, all antimicrobial feed additives must be subjected to the national assay before distribution. The current trends in assay acceptable amounts of feed additives (converted to bulk products) are shown in Figure 2. From 2000 to 2005 , the total volume was fairly constant, averaging 171 tons. Polyethers and polypeptides comprised a large percentage of feed additives (average of 97 and 44 tons, resp.), whereas those of other compounds, including tetracyclines, aminoglycosides, and macrolides, comprised less than $5 \%$ of the total volume (average of 6.8, 5.0, and 1.1 tons, resp.).

Presently, the total usage volume of antimicrobial drugs is much greater than that of antimicrobial feed additives in Japan. Thus, veterinary antimicrobial drugs are given priority as risk factors associated with bacterial antimicrobial resistance. 


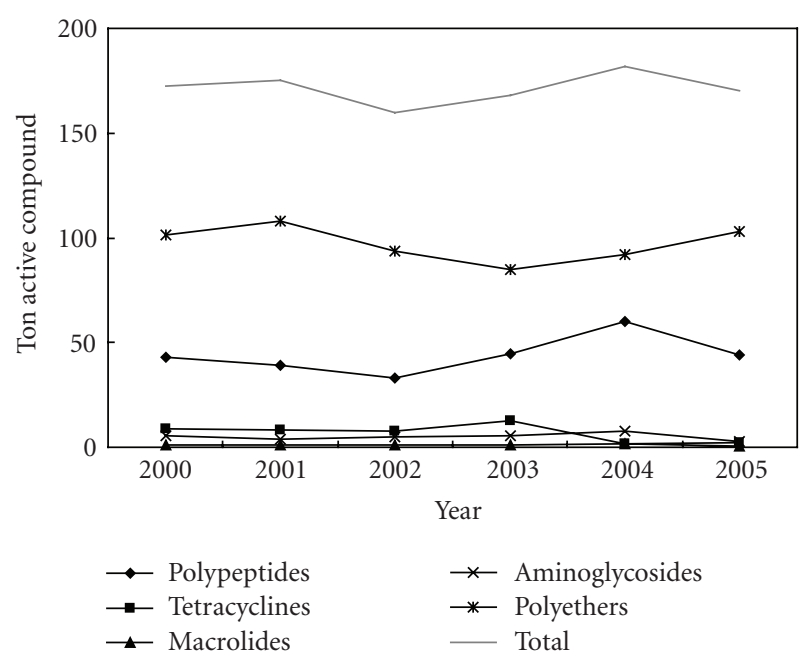

Figure 2: Trends in assay acceptable amounts of antimicrobial feed additives in Japan.

2.2. Relationship between the National Overall Usage Volume of Therapeutic Antimicrobials and the Prevalence of Antimicrobial-Resistant Bacteria. Few studies have provided an overview of the correlation between the usage volume of veterinary antimicrobials and the resistance rates among bacteria isolated from food-producing animals. In Japan, it was shown that the prevalence of resistance to a certain antimicrobial class among commensal E. coli isolates increased proportionately with the overall usage of the relevant class of drugs in each animal species [14]. When using data obtained from the DANMAP reports, the correlation was also represented between the usage volume of antimicrobial agents and the resistant population in $E$. coli observed in cattle and pigs [15]. Therefore, the national overall usage volume of therapeutic antimicrobials is likely to be related to the occurrence of antimicrobial resistance among commensal E. coli isolates from food-producing animals.

\subsection{The Prevalence of Antimicrobial Resistance Linked with} Species of Host Animal. In Japan, penicillins, tetracyclines, and streptomycins were classically approved and have been commonly used in animal husbandry for long periods. Figure 3 shows the current trends in resistances to these classical antimicrobials among commensal E. coli from foodproducing animals in Japan. From 2000 to 2007, the rates of resistances to these antimicrobials were stable in all three animal species, indicating that there is no significant change in the current usage volume of antimicrobials in foodproducing animals.

Comparison of the average resistance rates through the years revealed that the rate of ampicillin resistance was $46.0 \%$ in broilers, followed by pigs (27.3\%), and cattle (10.8\%). On the other hand, tetracycline and streptomycin resistance has been more frequently observed in broilers $(63.2 \%$ and $45.9 \%$, resp.) and pigs (65.5\% and $52.7 \%$, resp.), as compared with that in cattle $(31.4 \%$ and $23.6 \%$, resp.). Overall, the levels

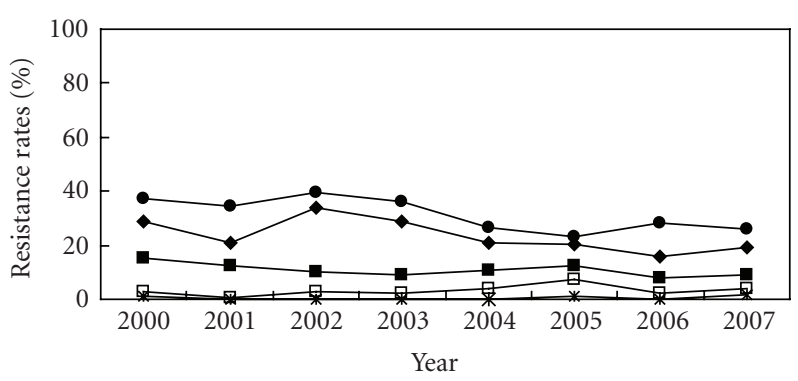

(a) Cattle

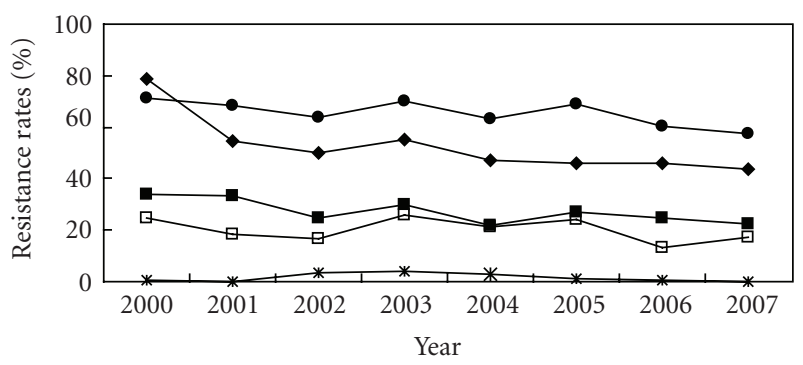

(b) Pigs

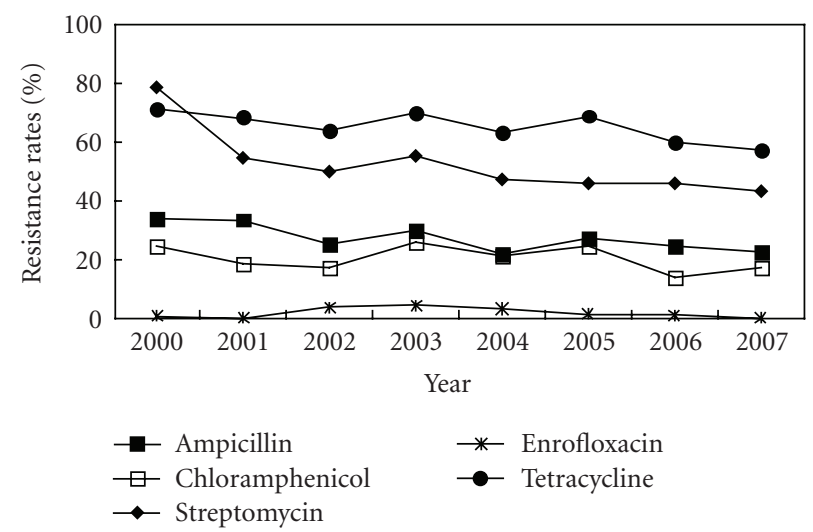

(c) Broiler chickens

Figure 3: Trends in resistance to selected antimicrobials among commensal E. coli isolates from cattle, pigs, and broiler chickens in Japan.

of resistance are apparently different between animal species and, in particular, resistance was less prevalent in cattle than in pigs and broilers.

The use of chloramphenicol in food-producing animals was banned in 1998 in Japan [16]. Nevertheless, current monitoring data shows that chloramphenicol resistance is still prevalent in pigs (average of 20.2\%), followed by chickens $(12.3 \%)$, and cattle (3.2\%). Thiamphenicol and florfenicol, which belong to the same family as chloramphenicol, are administered to food-producing animals with different usage volumes among animal species (pigs > chickens $>$ cattle). The use of these antimicrobials may be one factor causing the persistence of chloramphenicol resistance [16].

Overall, the levels of resistance to antimicrobials vary by animal species, and can be primarily affected by the usage 
volume of antimicrobials in each species [14]. Lower resistance levels of bacteria in cattle than in pigs and broilers have been commonly observed in case of all the antimicrobials, and this trend has remained largely unchanged since the start of monitoring [17-19]. In Japan, pigs and chickens are usually housed under relatively intensive conditions, whereas cattle are generally less intensively reared. In pigs or chickens, all the animals in the group or flock are preferably treated via feed or water because one can anticipate that infections will spread among multiple animals in the group or flock. On the other hand, in cattle, antimicrobials are usually administered orally or by injection to each affected animal. Thus, such animal species-specific management system probably produces the difference in the usage volume of antimicrobials, resulting in the biased prevalence of antimicrobial resistance among animal species.

2.4. The Trend in Antimicrobial Resistance in Commensal E. coli Isolates from Food-Producing Animals from Japan and Other Countries. The prevalence of antimicrobial resistance in commensal $E$. coli isolated from food-producing animals has been monitored in several countries including Japan. Here, the current trends in rates of resistance to older antimicrobials including penicillin, streptomycin, and tetracycline and newer antimicrobials including third-generation cephalosporins and fluoroquinolones among countries are summarized in Table 1(a) (cattle), Table 1(b) (pigs), and Table 1(c) (broilers).

Overall comparison of resistance rates against older antimicrobials including penicillin, streptomycin, and tetracycline revealed significant differences between countries. Isolates from all species in Sweden and Norway, and from cattle and broilers in Finland tended to show a lower prevalence of resistance than those in the other countries, which may have resulted from the comparatively lower overall usage of therapeutic antimicrobial compounds (approximately $17.2 \mathrm{t}, 6.5 \mathrm{t}$, and $14.1 \mathrm{t}$ in 2006 , resp.) $[26,39]$. On the other hand, isolates from all species in Japan showed moderate prevalence of resistance among countries. Considering the usage volume of antimicrobials, the resistance levels in Japan have been kept relatively low. In most countries, tetracycline resistance tended to be more prevalent than resistance to penicillin and streptomycin in all species. In Denmark, Norway, and Sweden, however, the prevalence of resistance to penicillin and/or streptomycin were equal to or more than that of tetracycline resistance.

Among animal species, bovine isolates exhibited generally lower levels of resistance to older antimicrobials than isolates from the other two species in most countries including Japan, with the exception of isolates from the Netherlands, where lower prevalence of resistance was observed in porcine isolates. This may suggest that antimicrobial usage for cattle tends to be less common in most countries, although there are variations in the degree of absolute usage volume among countries as described above.

The resistance to fluoroquinolone has essentially remained at low levels irrespective of countries or animal species. This may be explained by the attributive period of fluoroquinolone use because the agent was recently available in veterinary medicine. However, relatively high prevalence of resistance has been already observed in broilers in the Netherlands, Spain, and Korea and cattle in the Netherlands. The fluoroquinolone drugs are regarded as critically important antimicrobials in human and animal medicine internationally [13], and thus, the trend of its resistance would need continuous and careful observation.

The variation in antimicrobial resistance between different countries may be attributable to the quantity of the antimicrobial used, the time over which it had been available, the route or dosage by which it was administered, or some other epidemiological factors [30]. However, it remains possible that the variation between countries also includes disparities in monitoring methodologies [40]. In particular, older antimicrobials have been traditionally used as first-line drugs in veterinary medicine in a number of countries worldwide, and therefore, their resistance may greatly reflect country-specific antimicrobial usage. In response to the present state of resistance prevalence in each country, country-specific risk management would therefore be needed.

\section{Occurrence of Antimicrobial Resistance Including Cross-Resistance and Coresistance under Selective Pressure}

It is known that the application of a single drug may result not only in direct selection of the corresponding resistance but also in development of cross-resistance (the resistances to several structurally-related antimicrobials) and coresistance (the resistances to several structurally-unrelated antimicrobials), via specific resistance mechanisms $[2,41]$.

Some reports from the JVARM demonstrated the relationship between therapeutic antimicrobial use and the occurrence of bacterial antimicrobial resistance at a farm level.

3.1. Direct and Indirect Selections of Resistant E. coli due to OnFarm Use of Antimicrobial Drugs. To clarify the actual selections of resistance by veterinary antimicrobial use, a largescale epidemiological study was carried out by examining the rates of resistance to several antimicrobials among commensal E. coli isolates from pig herds with different histories of antimicrobial drug use [42]. Comparative analysis with the non-antimicrobial-exposed herd revealed that the rate of ampicillin resistance increased in the herds that were exposed to penicillin and penicillin-streptomycin; the rate of dihydrostreptomycin resistance, in the penicillin-streptomycinexposed herd; and the rate of trimethoprim resistance, in the methoprim-sulfonamide-exposed herd. Accordingly, each class of resistance was found more frequently in the herds exposed to the same antimicrobial classes than in those exposed to other antimicrobial classes (Figure 4). In the previous national-level analysis, the antimicrobial resistance rate of each class is correlated with the overall sales volume of the same antimicrobial class [14]. Thus, the use of the same class of antimicrobials, which can select 
TABLE 1

(a) Current trends in rates (\%) of resistance to selected antimicrobials in commensal E. coli isolates from cattle

\begin{tabular}{|c|c|c|c|c|c|c|}
\hline Country & Survey year & $\mathrm{PC}^{\mathrm{a}}$ & $\mathrm{SM}^{\mathrm{b}}$ & $\mathrm{TC}^{\mathrm{c}}$ & $\mathrm{FQ}^{\mathrm{d}}$ & References \\
\hline Japan $^{\mathrm{e}}$ & 2007 & 9.2 & 19.2 & 26.2 & 1.5 & {$[20]$} \\
\hline United States ${ }^{\mathrm{f}}$ & 2002-2003 & 2.5 & 10.2 & 23.1 & NT & {$[21]$} \\
\hline Canada & 2005 & 2.5 & 7.4 & 22.1 & 0.0 & {$[22]$} \\
\hline Denmark & 2006 & 2.2 & 10.8 & 9.7 & 0.0 & {$[23]$} \\
\hline France & 2004 & 14.0 & 20.0 & 26.0 & 0.0 & {$[24]$} \\
\hline Norway & 2005 & 2.0 & 9.2 & 1.0 & 0.0 & {$[25]$} \\
\hline Sweden & 2006 & 0.0 & 2.0 & 2.0 & $<1.0$ & {$[26]$} \\
\hline$U^{f}$ & 2004 & 3.0 & 2.0 & 6.0 & NT & {$[27]$} \\
\hline Netherlands & 2005 & 48.5 & NT & 82.4 & 25.5 & {$[28]$} \\
\hline Finland & 2006 & $<1.0$ & 3.0 & $<1.0$ & 1.0 & [29] \\
\hline Italy & 1999-2001 & 14.3 & 15.3 & 19.6 & 2.1 & {$[30]$} \\
\hline Germany & 1999-2001 & 1.7 & 3.7 & 6.5 & 0.0 & {$[30]$} \\
\hline Australia & 2003-2004 & 0.0 & NT & 3.0 & 0.0 & {$[31]$} \\
\hline Korea $^{\mathrm{f}}$ & 2003-2004 & 12.0 & 20.4 & 30.5 & 0.6 & {$[32]$} \\
\hline
\end{tabular}

${ }^{a} \mathrm{PC}$, penicillin antibiotics including ampicillin (MIC breakpoints, $16-32 \mathrm{mg} / \mathrm{L}$ ) and amoxicillin $(16 \mathrm{mg} / \mathrm{L})$.

${ }^{\mathrm{b}} \mathrm{SM}$, streptomycin antibiotics including streptomycin $(16-64 \mathrm{mg} / \mathrm{L})$ and dihydrostreptomycin $(32 \mathrm{mg} / \mathrm{L})$.

${ }^{\mathrm{C}} \mathrm{TC}$, tetracycline antibiotics including tetracycline and oxytetracycline $(16 \mathrm{mg} / \mathrm{L})$.

${ }^{\mathrm{d}} \mathrm{FQ}$, fluoroquinolone agents including ciprofloxacin $(0.125-4 \mathrm{mg} / \mathrm{L})$ and enrofloxacin $(0.125-2 \mathrm{mg} / \mathrm{L})$. In particular, some European countries like Denmark, Norway, Sweden, Netherlands, and Finland adopted low MIC breakpoints between 0.125 and $1.0 \mathrm{mg} / \mathrm{L}$.

${ }^{\mathrm{e}}$ In Japan, ampicillin, dihydrostreptomycin, oxytetracycline, and enrofloxacin were used as the representative of PC, SM, TC, and FQ, respectively, for susceptibility testing. As for ampicillin, the MIC breakpoint established by the Clinical Laboratory Standards Institute was adopted (32 mg/L) [33]; for the remaining antimicrobials, MIC breakpoints were set as the midpoint between the peaks of each MIC distribution (dihydrostreptomycin, $32 \mathrm{mg} / \mathrm{L}$; oxytetracycline, $16 \mathrm{mg} / \mathrm{L}$; enrofloxacin, $2 \mathrm{mg} / \mathrm{L}$ ) [34].

${ }^{\mathrm{f}}$ Susceptibility tests for all antimicrobials were performed by disk diffusion method.

(b) Current trends in rates (\%) of resistance to selected antimicrobials in commensal E. coli isolates from pigs

\begin{tabular}{|c|c|c|c|c|c|c|}
\hline Country & Survey year & $\mathrm{PC}^{\mathrm{a}}$ & $\mathrm{SM}^{\mathrm{b}}$ & $\mathrm{TC}^{\mathrm{c}}$ & $\mathrm{FQ}^{\mathrm{d}}$ & References \\
\hline Japan $^{\mathrm{e}}$ & 2007 & 22.6 & 43.4 & 57.5 & 0.0 & {$[20]$} \\
\hline United States ${ }^{\mathrm{f}}$ & 2002-2003 & 18.8 & 30.6 & 63.1 & NT & {$[21]$} \\
\hline Canada & 2005 & 34.6 & 38.9 & 74.7 & 0.6 & {$[22]$} \\
\hline Denmark & 2006 & 20.3 & 40.5 & 28.4 & 0.7 & {$[23]$} \\
\hline France & 2004 & 22.0 & 62.0 & 86.0 & 1.0 & {$[24]$} \\
\hline Norway & 2004 & 8.0 & 33.6 & 9.6 & 0.0 & {$[35]$} \\
\hline Sweden & 2005 & 6.0 & 14.0 & 9.0 & $<1.0$ & {$[26]$} \\
\hline$U^{f}$ & 2004 & 28.0 & 28.0 & 80.0 & NT & {$[27]$} \\
\hline Netherlands & 2005 & 30.4 & NT & 61.9 & 0.0 & {$[28]$} \\
\hline Spain $^{\mathrm{f}}$ & 2005 & 60.9 & 63.5 & 90.1 & 4.2 & {$[36]$} \\
\hline Australia & 2003-2004 & 35.0 & NT & 76.0 & 0.0 & {$[31]$} \\
\hline Korea & 2001-2003 & 75.2 & 85.7 & 99.2 & 7.5 & {$[37]$} \\
\hline Chile & 2003 & NT & 84.0 & 96.0 & 6.0 & {$[38]$} \\
\hline
\end{tabular}

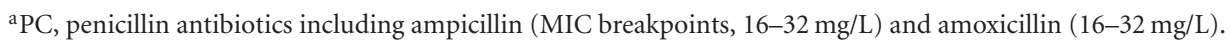

${ }^{\mathrm{b}} \mathrm{SM}$, streptomycin antibiotics including streptomycin $(16-64 \mathrm{mg} / \mathrm{L})$ and dihydrostreptomycin $(32 \mathrm{mg} / \mathrm{L})$.

${ }^{\mathrm{c}} \mathrm{TC}$, tetracycline antibiotics including tetracycline and oxytetracycline $(16 \mathrm{mg} / \mathrm{L})$.

${ }^{\mathrm{d}} \mathrm{FQ}$, fluoroquinolone agents including ciprofloxacin $(0.125-4 \mathrm{mg} / \mathrm{L})$ and enrofloxacin $(0.125-2 \mathrm{mg} / \mathrm{L})$. In particular, some European countries like Denmark, Norway, Sweden, and Netherlands adopted low MIC breakpoints between 0.125 and $1.0 \mathrm{mg} / \mathrm{L}$.

${ }^{\mathrm{e}}$ In Japan, ampicillin, dihydrostreptomycin, oxytetracycline, and enrofloxacin were used as the representative of PC, SM, TC, and FQ, respectively, for susceptibility testing. As for ampicillin, the MIC breakpoint established by the Clinical Laboratory Standards Institute was adopted (32 mg/L) [33]; for the remaining antimicrobials, MIC breakpoints were set as the midpoint between the peaks of each MIC distribution (dihydrostreptomycin, $32 \mathrm{mg} / \mathrm{L}$; oxytetracycline, $16 \mathrm{mg} / \mathrm{L}$; enrofloxacin, $2 \mathrm{mg} / \mathrm{L}$ ) [34].

fSusceptibility tests for all antimicrobials (the United States and UK) or streptomycin (Spain) were performed by disk diffusion method. 
(c) Current trends in rates (\%) of resistance to selected antimicrobials in commensal E. coli isolates from broilers

\begin{tabular}{|c|c|c|c|c|c|c|}
\hline Country & Survey year & $\mathrm{PC}^{\mathrm{a}}$ & $\mathrm{SM}^{\mathrm{b}}$ & $\mathrm{TC}^{\mathrm{c}}$ & $\mathrm{FQ}^{\mathrm{d}}$ & References \\
\hline $\operatorname{Japan}^{\mathrm{e}}$ & 2007 & 42.2 & 43.1 & 53.9 & 5.9 & [20] \\
\hline United States ${ }^{\mathrm{f}}$ & $2002-2003$ & 2.1 & 15.1 & 35.1 & NT & {$[21]$} \\
\hline Canada & 2005 & 38.5 & 43.1 & 57.3 & 0.0 & {$[22]$} \\
\hline Denmark & 2006 & 17.1 & 10.6 & 6.5 & 5.7 & [23] \\
\hline France & 2004 & 37.0 & 39.0 & 73.0 & 4.0 & [24] \\
\hline Norway & 2006 & 13.2 & 2.1 & 3.7 & 1.1 & [39] \\
\hline Sweden & 2004 & 4.0 & 6.0 & 6.0 & 2.0 & [26] \\
\hline $\mathrm{UK}^{\mathrm{f}}$ & 2004 & 37.0 & NT & 65.0 & 6.0 & [27] \\
\hline Netherlands & 2005 & 63.5 & NT & 60.9 & 50.8 & [28] \\
\hline Spain $^{f}$ & 2005 & 64.0 & 51.0 & 68.0 & 53.0 & {$[36]$} \\
\hline Finland & 2005 & 16.0 & 7.0 & 17.0 & 1.0 & [29] \\
\hline Australia & 2003-2004 & 33.0 & NT & 44.0 & 0.4 & [31] \\
\hline Korea & 2001-2003 & 63.8 & 86.5 & 80.4 & 50.1 & [37] \\
\hline Chile & 2003 & NT & 57.1 & 80.6 & 28.5 & [38] \\
\hline
\end{tabular}

${ }^{a} \mathrm{PC}$, penicillin antibiotics including ampicillin (MIC breakpoints, $16-32 \mathrm{mg} / \mathrm{L}$ ) and amoxicillin $(16-32 \mathrm{mg} / \mathrm{L}$ ).

${ }^{\mathrm{b}} \mathrm{SM}$, streptomycin antibiotics including streptomycin $(16-64 \mathrm{mg} / \mathrm{L})$ and dihydrostreptomycin $(32 \mathrm{mg} / \mathrm{L})$.

${ }^{\mathrm{c}} \mathrm{TC}$, tetracycline antibiotics including tetracycline and oxytetracycline $(16 \mathrm{mg} / \mathrm{L})$.

${ }^{\mathrm{d}} \mathrm{FQ}$, fluoroquinolone agents including ciprofloxacin $(0.125-4 \mathrm{mg} / \mathrm{L})$ and enrofloxacin $(0.125-2 \mathrm{mg} / \mathrm{L})$. In particular, some European countries like Denmark, Norway, Sweden, Netherlands, and Finland adopted low MIC breakpoints between 0.125 and $1.0 \mathrm{mg} / \mathrm{L}$.

${ }^{\mathrm{e}}$ In Japan, ampicillin, dihydrostreptomycin, oxytetracycline, and enrofloxacin were used as the representative of PC, SM, TC, and FQ, respectively, for susceptibility testing. As for ampicillin, the MIC breakpoint established by the Clinical Laboratory Standards Institute was adopted (32 mg/L) [33]; for the remaining antimicrobials, MIC breakpoints were set as the midpoint between the peaks of each MIC distribution (dihydrostreptomycin, $32 \mathrm{mg} / \mathrm{L}$; oxytetracycline, $16 \mathrm{mg} / \mathrm{L}$; enrofloxacin, $2 \mathrm{mg} / \mathrm{L}$ ) [34].

fSusceptibility tests for all antimicrobials (the United States and UK) or streptomycin (Spain) were performed by disk diffusion method.

the corresponding resistance and cross-resistance, strongly contributes to building the specific resistant population at the farm level and national level.

On the other hand, the rates of resistances to ampicillin, dihydrostreptomycin, kanamycin, and trimethoprim increased in the tetracycline-exposed herd and the rates of oxytetracycline and kanamycin resistances increased in the penicillin-streptomycin-exposed herd (Figure 4). These results raised the probability that the use of tetracycline or penicillin-streptomycin antibiotics contributed to the selection of other resistances linking resistance to the antimicrobials used, and that the tetracycline use could coselect for the most extensive resistances in commensal E. coli isolates of pig origin. Annual reports reveal that tetracyclines have been used in the largest quantities in Japan [11], and therefore, tetracycline resistance has been the most prevalent in E. coli of pig origin $[43,44]$. In addition, Sunde and Norström [45] demonstrated the cotransfer of determinants of resistances to tetracycline and other antimicrobials via plasmids in E. coli isolated from meat products. Thus, the coselective force imposed by tetracycline use would likely have a significant impact on the prevalence of resistance to extensive antimicrobials in E. coli in food-producing animals.

Generally, coselection is closely associated with coresistance that is encoded by different resistance determinants gathered on a single mobile genetic element including plasmid and transposon $[2,41]$. This suggests that resistances acquired by chromosomal mutation of the target site, such as quinolone resistance, are difficult to be coselected by

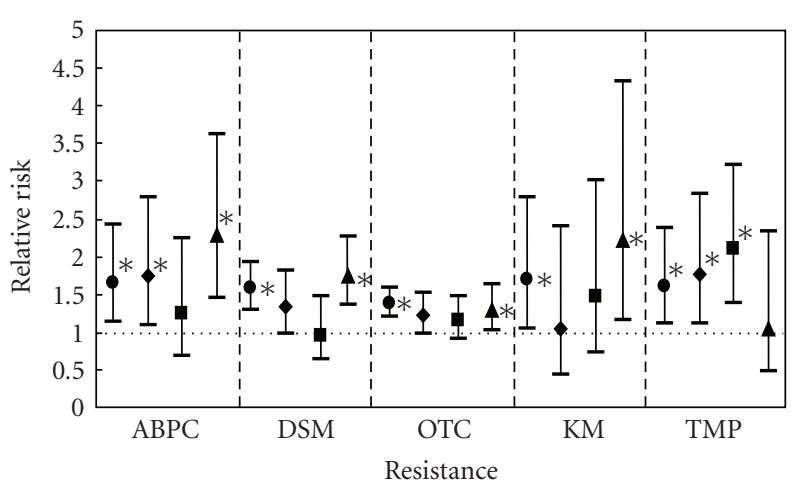

FIGURE 4: Relative risks of antimicrobial resistance in porcine E. coli isolates due to exposure to antimicrobials mainly used in Japan. ${ }^{a}$ Symbols indicate the values of relative risk of each resistance due to exposure to tetracycline antibiotics $(\bullet)$, penicillin antibiotics $(\boldsymbol{\Delta})$, methoprims-sulfonamides combination drugs $(\downarrow)$, and penicillinstreptomycin combination drugs $(\boldsymbol{\square}) .{ }^{*}$ In case that $95 \%$ confidence interval ( $\mathbf{I}$ ) does not include the value 1 , the relative risk is considered statistically significant $(P<.05)$. This figure is based on the data obtained from the previous manuscript mentioned in [42].

use of other antimicrobials. The farm-level monitoring data of Campylobacter, however, raised the possibility that fluoroquinolone-resistant isolates with multi-antimicrobial resistance have been coselected by use of the antimicrobials included by their resistance pattern like tetracyclines [46]. 
Thus, even resistance acquired by gene mutation can be coselected through multiple-antimicrobial resistance in bacteria.

The direct selection of the corresponding resistance and indirect selection via cross-resistance and coresistance significantly can contribute to the farm-level prevalence of antimicrobial-resistant bacteria. In indirect selection, the use of antimicrobials can select cross-resistance more greatly than coresistance in bacteria. Thus, the antimicrobial drugs classified into the same class as important drugs should be actively controlled. On the other hand, it may also be necessary that special attention is given to the use of antimicrobial drugs that can cause coselection to further minimize the prevalence of antimicrobial-resistant bacteria.

\subsection{Contribution of Coselection to the Persistence of Resistance} to Specific Antimicrobials in the Absence of Selective Pressure. In Japan, the use of several antimicrobials in food-producing animals was banned because of human health issues posed by their toxic effects. In particular, the use of carbadox was banned in 1997, followed by the ban on frazolidone, difurazon, and chloramphenicol in 1998. It is believed that the ban of antimicrobial use will help prevent the development of antimicrobial resistance in bacteria. However, in the absence of selective pressure, specific antimicrobial resistance becomes prevalent in food-producing animals.

The JVARM study showed that $40.6 \%$ of E. coli isolated from diseased animals was resistant to chloramphenicol after the ban of its use [16]. By the further detailed investigation, it was clarified that strains with the chloramphenicol resistance genes that were isolated from diseased cattle often were resistant to ampicillin, dihydrostreptomycin, oxytetracycline, and trimethoprim, and those that were isolated from diseased pigs were often resistant to dihydrostreptomycin and trimethoprim. Class 1 integrons, which were responsible for resistance(s) to streptomycins, methoprims, or both, were more prevalent in strains with than those without the chloramphenicol resistance genes. Therefore, selective pressure imposed by the use of other common antimicrobials may contribute to the coselection of chloramphenicolresistant E. coli in Japan. Bischoff et al. [47] confirmed that resistance to sulfamethoxazole, tetracycline, and kanamycin frequently transferred along with chloramphenicol resistance through genetic linkage between their resistance genes in porcine E. coli isolates, and suggested that chloramphenicol resistance has been maintained by the use of antimicrobials that are currently approved, as well as our presumption. These findings suggest the possibility that, even in the absence of specific selective pressure due to the use of phenicols, chloramphenicol resistance remains so long as other antimicrobials are used in food-producing animals.

For resistance to antimicrobials other than chloramphenicol, coselection contributes to the persistence in the absence of selective pressure. In Japan, while no cephalosporins are approved for use in poultry, cefazolinresistant $E$. coli strains, which harbored extended-spectrum class $\mathrm{A}$ or class $\mathrm{C} \beta$-lactamase on plasmid, have been isolated from broiler chickens [48]. These $\beta$-lactamase genes were transferred with other antimicrobial resistance genes, suggesting that expended-spectrum $\beta$-lactamase producing E. coli are currently maintained by other antimicrobial use. Other studies clarified that plasmids with resistances to carbadox and the other drugs were prevalent in porcine E. coli isolates [49], and thus carbadox-resistant isolates can continue to be coselected after the ban of carbadox. For enterococci, Bager et al. [50] showed the persistence of glycopeptide-resistant enterococci in Danish pigs after the ban of the use of avoparcin. It is suggested that the glycopeptide resistance gene in swine enterococcal strains was selected by the use of macrolides via cotransfer with macrolide resistance genes [51].

It is suggested that the withdrawal of antimicrobials in order to decrease rates of resistance is not always an effective strategy for restoration of the therapeutic effectiveness of a specific drug. Simultaneous reductions in the selection pressures of coselecting agents may be required to reduce the emergence, spread, and persistence of antimicrobial resistance in the animal production environment.

\section{Association of Antimicrobial Resistance Profile with Bacterial Properties}

The pathogenicity of bacteria, including E. coli, is often characterized by intrinsic properties such as virulence factors and serotypes. Clinical signs, being associated with the pathogenic properties of bacteria, may affect the scenario of antimicrobial treatment. Information on antimicrobial resistance in animal bacterial pathogen is therefore helpful not merely for adequate selection and prudent use of antimicrobial agents in veterinary medicine but also comprehension about the relationship between bacterial properties and antimicrobial resistance profile.

4.1. The Prevalence of Antimicrobial Resistance in Pathogenic E. coli. Antimicrobial susceptibilities in pathogenic E. coli isolates from diseased animals with colibacillosis were investigated under the JVARM. In particular, resistance to commonly used antimicrobials, including ampicillin, dihydrostreptomycin, and oxytetracycline, was highly prevalent in the isolates from diseased animals $[52,53]$. Compared with commensal E. coli isolates from apparently healthy animals [17], those from diseased animals showed higher rates of resistance to most or some of the antimicrobials tested. Similarly, in the DANMAP report [23], higher prevalence of resistance was observed in E. coli isolated from diagnostic submissions compared to the bacterium from healthy animals. On the whole, the pathogenic isolates from diseased animal are likely to have greater resistances, which may be a consequence of antimicrobial treatment in veterinary medicine.

Pathogenic E. coli can be characterized by their specific pathogenic mechanisms like toxins, adhesins, and invasiveness [54]. In particular, shiga toxins-producing $E$. coli (STEC) and enterotoxigenic E. coli (ETEC) have been implicated in a number of specific diseases in animals [55]. Under the JVARM, resistance to colistin and enrofloxacin was more prevalent in STEC isolates, mainly harboring stx2e 
gene, than in non-STEC isolates from diseased pigs [52]. Meanwhile, there was no relationship between antimicrobial resistance prevalence and virulence factors tested in the isolates from diseased cattle and chickens $[52,53]$.

On the other hand, Boerlin et al. [56] confirmed that resistance to most antimicrobials tested was higher in ETEC than in non-ETEC isolates from pigs with diarrhea in Ontario and that statistically positive association existed between resistance genes for tetracycline, sulfonamides, and apramycin and major virulence genes including elt, est $A$, est $B$, fae $G, p a a$, and sep $A$. In addition, substantial linkages between antimicrobial resistance genes and specific virulence genes on large transferable plasmids have been described occasionally in the past for ETEC isolates from swine and calves [57-60] and for APEC [61] in several countries. These data indirectly or directly suggest the relationship between virulence and resistance genes.

Higher prevalence of antimicrobial resistance in pathogenic bacteria can be primarily explained by the possible contribution of increased selective pressure by repeated exposure to therapeutic agents. In addition, strong relationship between resistance and virulence factors also likely contributes to the spread of antimicrobial resistance among pathogenic bacteria. These facts should be taken into account in risk management for antimicrobial-resistant bacterial pathogen in veterinary medicine.

\subsection{Prevalence of Antimicrobial Resistance among Serotypes of} Bacteria. Serotyping is used extensively to categorize strains of E. coli. There are $174 \mathrm{O}$ antigens and $53 \mathrm{H}$ antigens in the international serotyping scheme, with $E$. coli isolates having various combinations of $\mathrm{O}$ and $\mathrm{H}$ antigens [55]. However, data on the relationship between antimicrobial resistance profiles and serotypes in E. coli are still limited.

Under the JVARM, there are some findings about the association with serotypes. In the survey of STEC in cattle, it was shown that multiple resistance was relatively frequently observed in certain serotypes like O2: NM, O26:H11/NM, $\mathrm{O} 145: \mathrm{NM}$, and $\mathrm{O} 174: \mathrm{NM} / \mathrm{H} 21$, which are nonpathogenic for animals [62]. In addition, the field study on APEC showed that more than half of enrofloxacin-resistant strains belonged to serotype O78, which is one of the most common serotypes in APEC, with a similar genotype [53]. In Europe, it is reported that the STEC O118:H16/NM strains with multi-antimicrobial resistance have spread clonally in cattle and humans [63].

For other bacterial species, Salmonella serovars Dublin, Typhimurium and Choleraesuis are regarded as serotypes causing salmonellosis in farm animals. These serotypes, harboring the specific plasmid responsible for virulence in mice [64], commonly have high frequency of resistance to antimicrobials like ampicillin, streptomycin, and tetracycline [65-68]. Other serotypes like Infantis and Schwarzengrund have relatively low pathogenicity for farm animals, but exhibit the specific resistance patterns [69-71]. In addition, in Campylobacter jejuni, biased prevalence of antimicrobial resistance has also been observed among serotypes, although the bacterium is usually not pathogenic in animals [72].
The dissemination of serotypes with characteristic resistance profiles could be a factor biasing the antimicrobial resistance prevalence in bacteria. However, there are not enough evidences to fully comprehend the causal association between serotypes and antimicrobial resistance profile in bacteria. The trend of antimicrobial resistance among serotypes in bacteria should be therefore monitored carefully.

\section{Future Issue}

Several countries have already launched national level monitoring for risk analysis of antimicrobial resistance in foodproducing animals. In some countries, veterinary use of some antimicrobials is regulated by new decisions such as ban of fluoroquinolone use in poultry in the United States, and antimicrobial growth promoter in European Union. National level monitoring helps to realize broad prevalence of antimicrobial resistance: however, it is unable to fully figure out variability of antimicrobial resistance prevalence among farms or among herds and individuals on a farm. Detection of antimicrobial-resistant bacteria on farms usually means that the bacteria have developed antimicrobial resistance by genetic mutations or acquisition of resistance genes [41], and other resistant clones have intruded into the farms [73]. In either case, the use of antimicrobials frequently acts as selective force. In addition, occurrence and prevalence of antimicrobial resistance were affected by multiple factors including feeding system and practices on farms [74-77], age [74, 78, 79], pharmacodynamics [80], stress $[81,82]$, and commensal flora [83] for individuals. Such investigation on farm-level epidemiology to profile risk of development of antimicrobial resistance is important for controlling antimicrobial resistance on farms.

At present, national level monitoring is limited to elucidate all of the factors that contribute to antimicrobial resistance prevalence. In Japan, as described in this review, contradictory results between antimicrobial resistance prevalence and antimicrobial use are obtained in the national veterinary monitoring. Especially, resistance to critically important antimicrobials such as fluoroquinolones and cephalosporins [13] may need to be preferentially monitored not only at national level but also on farm or at individual level for making assured risk management decisions. Hereafter, further detailed monitoring may be implemented in veterinary field. The following steps are recommended: (1) national (or district) level monitoring, (2) farm level monitoring, and (3) individual (or herd) level monitoring. These efforts will develop conservative risk management strategies of antimicrobial resistance.

\section{Conclusion}

Multiple factors appear to participate in the occurrence and prevalence of antimicrobial-resistant bacteria under the selective pressure from antimicrobial usage. It is supported by the national-level and farm-level data that the direct resistance selection or indirect selection via cross-resistance greatly contributes to antimicrobial resistance prevalence. 
In other words, the prevalence of a specific resistance can be controlled by the regulation of the corresponding class of antimicrobial drug. Such a strategy probably leads to a successful outcome. On the other hand, the affection of coresistance may lead to unexpected results. Without the knowledge on actual magnitude of coresistance, judicious regulation of the usage of all the antimicrobials that can select the resistance might be needed to control coresistance. This direction involves issues that greatly threaten animal health and welfare. Therefore, the risk manager should initially collect practical data on the effect of coresistance, and select the risk management option to balance cross-resistance and coresistance.

Moreover, the JVARM data, which may be limited, suggested that the bacterial property like virulence factors and serotypes sometimes affect the prevalence of antimicrobial resistance in E. coli and other bacterial species of animal origin. However, the relationship between these factors and resistance has been inconsistently reported by each researcher, and thus it would be needed to continue to carefully monitor its relationship in addition to other known bacterial properties like intrinsic fitness [84-86].

Finally, this paper first revealed current situation of veterinary antimicrobial usage and prevalence of antimicrobialresistant E. coli isolates from food-producing animals in Japan. In addition, the contributing factors, mainly antimicrobial selective pressure, were described based on hitherto obtained data. It is hoped that this paper will assist an understanding of epidemiology of antimicrobial resistance as much as possible.

\section{References}

[1] F. M. Aarestrup, "Association between the consumption of antimicrobial agents in animal husbandry and the occurrence of resistant bacteria among food animals," International Journal of Antimicrobial Agents, vol. 12, no. 4, pp. 279-285, 1999.

[2] S. Schwarz, C. Kehrenberg, and T. R. Walsh, "Use of antimicrobial agents in veterinary medicine and food animal production," International Journal of Antimicrobial Agents, vol. 17, no. 6, pp. 431-437, 2001.

[3] Anonymous, Report of the Joint Committee on the Use of Antibiotics in Animal Husbandry and Veterinary Medicine, HMSO, London, UK, 1969.

[4] T. Asai, "Antimicrobial usage and resistant bacteria in foodproducing animals," Annual report of the National Veterinary Assay Laboratory, vol. 42, pp. 1-8, 2005.

[5] P. Dehaumont, "OIE international standards on antimicrobial resistance," Journal of Veterinary Medicine Series B, vol. 51, no. 8-9, pp. 411-414, 2004.

[6] S. H. Doyran, "Risk analysis of antibiotic resistance, Berlin, BfR, 10-12 November 2003: activities of the codex alimentarius commission related to antibiotic resistance," Journal of Veterinary Medicine Series B, vol. 51, no. 8-9, pp. 408-410, 2004.

[7] World Organisation for Animal Health (OIE), “OIE guidelines on antimicrobial resistance: reports prepared by the OIE Ad hoc group of experts on antimicrobial resistance," Revue Scientifique et Technique (International Office of Epizootics), vol. 20, pp. 797-870, 2003.
[8] FAO/OIE/WHO, "Joint FAO/OIE/WHO expert workshop on non-human antimicrobial usage and antimicrobial resistance: scientific assessment," 2004, http://www.who.int/foodsafety/publications/micro/en/amr.pdf.

[9] FAO/OIE/WHO, "Second joint FAO/OIE/WHO expert workshop on non-human antimicrobial usage and antimicrobial resistance: management options," 2004, http://www.who.int/ foodsafety/publications/micro/en/oslo_report.pdf.

[10] Y. Tamura, "The Japanese veterinary antimicrobial resistance monitoring system (JVARM)," in OIE international standards on Antimicrobial Resistance, V. Bernard, Ed., pp. 206-210, OIE (World organization for animal health), Paris, France, 2003.

[11] Y. Tamura, "Trends in antimicrobial agents for veterinary use and control measures of antimicrobial resistance," Journal of the Japan Veterinary Medical Association, vol. 56, pp. 685-691, 2003.

[12] A. A. Valois, Y. S. Endoh, K. Grein, and L. Tollefson, "Geographical differences in market availability, regulation and use of antimicrobial products," in Guide to Antimicrobial Use in Animals, L. Guardabassi, L. B. Jensen, and H. Kruse, Eds., pp. 59-76, Willey-Blackwell, Bognor, UK, 2008.

[13] FAO/WHO/OIE, "Joint FAO/OIE/WHO Expert Meeting on Critically Important Antimicrobials," Report of a meeting held in FAO, Rome, Italy, November 2007, Geneva, Switzerland, 2008, http://www.who.int/foodborne_disease/ resources/Report\%20joint\%20CIA\%20Meeting.pdf.

[14] T. Asai, A. Kojima, K. Harada, K. Ishihara, T. Takahashi, and Y. Tamura, "Correlation between the usage volume of veterinary therapeutic antimicrobials and resistance in Escherichia coli isolated from the feces of food-producing animals in Japan," Japanese Journal of Infectious Diseases, vol. 58, no. 6, pp. 369372, 2005.

[15] DANMAP, “DANMAP 2001 Use of Antimicrobial Agents and Occurrence of Antimicrobial Resistance in Bacteria from Food Animals, Foods and Humans in Denmark," 2002, http://www.danmap.org/pdfFiles/Danmap_2001.pdf.

[16] K. Harada, T. Asai, A. Kojima, K. Ishihara, and T. Takashi, "Role of coresistance in the development of resistance to chloramphenicol in Escherichia coli isolated from sick cattle and pigs," American Journal of Veterinary Research, vol. 67, no. 2, pp. 230-235, 2006.

[17] M. Kijima-Tanaka, K. Ishihara, A. Morioka, et al., "A national surveillance of antimicrobial resistance in Escherichia coli isolated from food-producing animals in Japan," Journal of Antimicrobial Chemotherapy, vol. 51, no. 2, pp. 447-451, 2003.

[18] T. Asai, H. Esaki, A. Kojima, K. Ishihara, Y. Tamura, and T. Takahashi, "Antimicrobial resistance in Salmonella isolates from apparently healthy food-producing animal from 2000 to 2003: the first stage of Japanese Veterinary Antimicrobial Resistance Monitoring (JVARM)," Journal of Veterinary Medical Science, vol. 68, no. 8, pp. 881-884, 2006.

[19] A. Kojima, A. Morioka, M. Kijima, et al., "Classification and antimicrobial susceptibilities of Enterococcus species isolated from apparently healthy food-producing animals in Japan," Zoonoses and Public Health, vol. 57, no. 2, pp. 137-141, 2010.

[20] T. Asai, R. Koike, A. Kojima, et al., "An epidemiological study of antimicrobial resistance in bacteria isolated from domestic animals in Japan," Reports from National Veterinary Assay Laboratory, vol. 45, pp. 45-52, 2008.

[21] R. S. Sayah, J. B. Kaneene, Y. Johnson, and R. Miller, "Patterns of antimicrobial resistance observed in Escherichia coli isolates obtained from domestic- and wild-animal fecal samples, human septage, and surface water," Applied and Environmental Microbiology, vol. 71, no. 3, pp. 1394-1404, 2005. 
[22] CIPARS, "CIPARS 2005 Canadian Integrated Program for Antimicrobial Resistance Surveillance," Public Health Agency of Canada, 2006, http://www.phac-aspc.gc.ca/cipars-picra/ pdf/cipars-picra-2005_e.pdf.

[23] DANMAP, "DANMAP 2006 Use of Antimicrobial Agents and Occurrence of Antimicrobial Resistance in Bacteria from Food Animals, Foods and Humans in Denmark," 2007, http://www.danmap.org/pdfFiles/Danmap_2006.pdf.

[24] FARM, "FARM 2003-2004 French antimicrobial resistance monitoring in bacteria of animal origin," French Food Safety Agency, French, 2006, http://www.afssa.fr/Documents/SANTRa-FARM.pdf.

[25] NORM/NORM-VET, "NORM/NORM-VET 2005 Usage of antimicrobial agents and occurrence of antimicrobial resistance in Norway," National Veterinary Institute, 2006, http ://www.vetinst.no/eng/Research/Publications/Norm-NormVet-Report/The-Norm-Norm-Vet-Report-2005.

[26] SVARM, "SVARM 2006, Swedish Veterinary Antimicrobial Resistance Monitoring," 2007, http://www.sva.se/upload/pdf/ Tj\%C3\%A4nster\%20och\%20produkter/Trycksaker/svarm -2006.pdf.

[27] DEFRA (Department for Environment, Food and Rural Affairs), "Report on the trends and sources of zoonoses and zoonotic agents in humans, foodstuffs, animals and feeding stuffs in 2004,” 2005, http://www.defra.gov.uk/animalh/ diseases/zoonoses/zoonoses_reports/report2004uk.pdf.

[28] MARAN, "MARAN 2005 Monitoring of Antimicrobial Resistance and Antibiotic Usage in Animals in the Netherlands in 2005," The Veterinary Antibiotic Usage and Resistance Surveillance Working Group, 2006, http://www.cvi.wur.nl/ NR/rdonlyres/A906A4C0-A458-423E-B932-28F222385988/ 52533/MARAN2005def.pdf.

[29] FINRES-Vet, "FINRES-Vet 2005-2006 Finnish Veterinary Antimicrobial Resistance Monitoring and Consumption of Antimicrobial Agents," Finnish Food Safety Authority Evira, Finland, 2007, http://www.crl-ar.dana9.dk/data/images/ moni/FINRES-Vet_2005-2006_web.pdf.

[30] R. Bywater, H. Deluyker, E. Deroover, et al., "A European survey of antimicrobial susceptibility among zoonotic and commensal bacteria isolated from food-producing animals," Journal of Antimicrobial Chemotherapy, vol. 54, no. 4, pp. 744754, 2004.

[31] DAFF (Department of Agriculture, Fisheries and Forestry), "Pilot Surveillance Program for Antimicrobial Resistance in Bacteria of Animal Origin," Australian Government Department of Agriculture, Fisheries and Forestry, Canberra, 2007, http://www.daff.gov.au/_data/assets/pdf_file/0004/ 950431/AMR-pilot-survey-report.pdf.

[32] S.-K. Lim, H.-S. Lee, H.-M. Nam, et al., "Antimicrobial resistance observed in Escherichia coli strains isolated from fecal samples of cattle and pigs in Korea during 2003-2004," International Journal of Food Microbiology, vol. 116, no. 2, pp. 283-286, 2007.

[33] Clinical and Laboratory Standards Institute, Performance standards for antimicrobial susceptibility testing: Seventeeth informational suspplement. M100-S17, vol. 27, Clinical and Laboratory Standards Institute, Wayne, Pa, USA, 2007.

[34] Working Party of the British Society for Antimicrobial Chemotherapy, "A guide to sensitivity testing," Journal of Antimicrobial Chemotherapy, vol. 38, pp. 1103-1105, 1996.

[35] NORM/NORM-VET, "NORM/NORM-VET 2004 Usage of antimicrobial agents and occurrence of antimicrobial resistance in Norway," National Veterinary Institute, 2005, http://www.vetinst.no/eng/Research/Publications/Norm-Norm-Vet-Report/The-Norm-Norm-Vet-Report-2004.

[36] VAV, "VAV 2005 Veterinary monitoring of antimicrobial resistance in Spain," Centro de Vigilancia Sanitaria Veterinaria, Spain, 2006, http://www.vigilanciasanitaria.es/ data/VAV2005.pdf.

[37] H. Y. Kang, Y. S. Jeong, J. Y. Oh, et al., "Characterization of antimicrobial resistance and class 1 integrons found in Escherichia coli isolates from humans and animals in Korea," Journal of Antimicrobial Chemotherapy, vol. 55, no. 5, pp. 639644, 2005.

[38] B. S. Martin, L. Campos, V. Bravo, M. Adasne, and C. Borie, "Evaluation of antimicrobial resistance using indicator bacteria isolated from pigs and poultry in Chile," The International Journal of Applied Research in Veterinary Medicine, vol. 3, pp. 171-178, 2005.

[39] NORM/NORM-VET, "NORM/NORM-VET 2006 Usage of antimicrobial agents and occurrence of antimicrobial resistance in Norway," 2007, http://www.vetinst.no/eng/ Research/Publications/Norm-Norm-Vet-Report/The-Norm-Report-2006.

[40] F. M. Aarestrup, "Monitoring of antimicrobial resistance among food animals: principles and limitations," Journal of Veterinary Medicine Series B, vol. 51, no. 8-9, pp. 380-388, 2004.

[41] B. Catry, H. Laevens, L. A. Devriese, G. Opsomer, and A. De Kruif, "Antimicrobial resistance in livestock," Journal of Veterinary Pharmacology and Therapeutics, vol. 26, no. 2, pp. 81-93, 2003.

[42] K. Harada, T. Asai, M. Ozawa, A. Kojima, and T. Takahashi, "Farm-level impact of therapeutic antimicrobial use on antimicrobial- resistant populations of Escherichia coli isolates from pigs," Microbial Drug Resistance, vol. 14, no. 3, pp. 239244, 2008.

[43] K. Harada, T. Asai, A. Kojima, T. Sameshima, and T. Takahashi, "Contribution of multi-antimicrobial resistance to the population of antimicrobial resistant Escherichia coli isolated from apparently healthy pigs in Japan," Microbiology and Immunology, vol. 51, no. 5, pp. 493-499, 2007.

[44] A. Kojima, T. Asai, K. Ishihara, et al., "National monitoring for antimicrobial resistance among indicator bacteria isolated from food-producing animals in Japan," Journal of Veterinary Medical Science, vol. 71, no. 10, pp. 1301-1308, 2009.

[45] M. Sunde and M. Norström, "The prevalence of, associations between and conjugal transfer of antibiotic resistance genes in Escherichia coli isolated from Norwegian meat and meat products," Journal of Antimicrobial Chemotherapy, vol. 58, no. 4, pp. 741-747, 2006.

[46] T. Asai, K. Harada, K. Ishihara, et al., "Association of antimicrobial resistance in Campylobacter isolated from foodproducing animals with antimicrobial use on farms," Japanese Journal of Infectious Diseases, vol. 60, no. 5, pp. 290-294, 2007.

[47] K. M. Bischoff, D. G. White, P. F. McDermott, et al., "Characterization of chloramphenicol resistance in $\beta$-hemolytic Escherichia coli associated with diarrhea in neonatal swine," Journal of Clinical Microbiology, vol. 40, no. 2, pp. 389-394, 2002.

[48] A. Kojima, Y. Ishii, K. Ishihara, et al., "Extended-spectrum$\beta$-lactamase-producing Escherichia coli strains isolated from farm animals from 1999 to 2002: report from the Japanese veterinary antimicrobial resistance monitoring program," 
Antimicrobial Agents and Chemotherapy, vol. 49, no. 8, pp. 3533-3537, 2005.

[49] K. Ohmae, S. Yonezawa, and N. Terakado, "R plasmid with carbadox resistance from Escherichia coli of porcine origin," Antimicrobial Agents and Chemotherapy, vol. 19, no. 1, pp. 8690, 1981.

[50] F. Bager, F. M. Aarestrup, M. Madsen, and H. C. Wegener, "Glycopeptide resistance in Enterococcus faecium from broilers and pigs following discontinued use of avoparcin," Microbial Drug Resistance, vol. 5, no. 1, pp. 53-56, 1999.

[51] F. M. Aarestrup, "Characterization of glycopeptide-resistant Enterococcus faecium (GRE) from broilers and pigs in Denmark: genetic evidence that persistence of GRE in pig herds is associated with coselection by resistance to macrolides," Journal of Clinical Microbiology, vol. 38, pp. 2774-2777, 2000.

[52] K. Harada, T. Asai, A. Kojima, C. Oda, K. Ishihara, and T. Takahashi, "Antimicrobial susceptibility of pathogenic Escherichia coli isolated from sick cattle and pigs in Japan," Journal of Veterinary Medical Science, vol. 67, no. 10, pp. 9991003, 2005.

[53] M. Ozawa, K. Harada, A. Kojima, T. Asai, and T. Sameshima, "Antimicrobial susceptibilities, serogroups, and molecular characterization of avian pathogenic Escherichia coli isolates in Japan," Avian Diseases, vol. 52, no. 3, pp. 392-397, 2008.

[54] E. A. González Garcia, "Animal health and foodborne pathogens: enterohaemorrhagic O157:H7 strains and other pathogenic Escherichia coli virotypes (EPEC, ETEC, EIEC, EHEC)," Polish Journal of Veterinary Sciences, vol. 5, pp. 103 $115,2002$.

[55] C. L. Gyles, "Shiga toxin-producing Escherichia coli: an overview," Journal of Animal Science, vol. 85, pp. E45-E62, 2007.

[56] P. Boerlin, R. Travis, C. L. Gyles, et al., "Antimicrobial resistance and virulence genes of Escherichia coli isolates from swine in Ontario," Applied and Environmental Microbiology, vol. 71, no. 11, pp. 6753-6761, 2005.

[57] A. J. Mazaitis, R. Maas, and W. K. Maas, "Structure of a naturally occurring plasmid with genes for enterotoxin production and drug resistance," Journal of Bacteriology, vol. 145, no. 1, pp. 97-105, 1981.

[58] A. Franklin and R. Mollby, "Concurrent transfer and recombination between plasmids encoding for heat-stable enterotoxin and drug resistance in porcine enterotoxigenic. Escherichia coli," Medical Microbiology and Immunology, vol. 172, no. 3, pp. 137-147, 1983.

[59] N. M. Harnett and C. L. Gyles, "Linkage of genes for heatstable enterotoxins, drug resistance, K99 antigen, and colicin in bovine and porcine strains of enterotoxigenic Escherichia coli," American Journal of Veterinary Research, vol. 46, pp. 428433, 1985.

[60] R. M. Travis, C. L. Gyles, R. Reid-Smith, et al., "Chloramphenicol and kanamycin resistance among porcine Escherichia coli in Ontario," Journal of Antimicrobial Chemotherapy, vol. 58, no. 1, pp. 173-177, 2006.

[61] T. J. Johnson, C. W. Giddings, S. M. Horne, et al., "Location of increased serum survival gene and selected virulence traits on a conjugative R plasmid in an avian Escherichia coli isolate," Avian Diseases, vol. 46, no. 2, pp. 342-352, 2002.

[62] M. Kijima-Tanaka, K. Ishihara, A. Kojima, et al., "A national surveillance of Shiga toxin-producing Escherichia coli in foodproducing animals in Japan," Journal of Veterinary Medicine Series B, vol. 52, no. 5, pp. 230-237, 2005.
[63] H. Maidhof, B. Guerra, S. Abbas, H. M. Elsheikha, T. S. Whittam, and L. Beutin, "A multiresistant clone of Shiga toxin-producing Escherichia coli O118:[H16] is spread in cattle and humans over different European countries," Applied and Environmental Microbiology, vol. 68, no. 12, pp. 5834-5842, 2002.

[64] P. A. Gulig, "Mini-review: virulence plasmids of Salmonella typhimurium and other salmonellae," Microbial Pathogenesis, vol. 8, no. 1, pp. 3-11, 1990.

[65] H. Yoshimura, Y. S. Endoh, M. Ishimaru, and M. Takagi, "Antimicrobial resistance patterns of Salmonella typhimurium and Salmonella dublin isolated from cattle in Japan," Veterinary Record, vol. 147, no. 2, pp. 48-50, 2000.

[66] H. Esaki, A. Morioka, A. Kojima, et al., "Epidemiological characterization of Salmonella typhimurium DT104 prevalent among food-producing animals in the Japanese veterinary antimicrobial resistance monitoring program (1999-2001)," Microbiology and Immunology, vol. 48, no. 7, pp. 553-556, 2004.

[67] K. Kawagoe, H. Mine, T. Asai, et al., "Changes of multi-drug resistance pattern in Salmonella enterica subspecies enterica serovar typhimurium isolates from food-producing animals in Japan," Journal of Veterinary Medical Science, vol. 69, no. 11, pp. 1211-1213, 2007.

[68] T. Asai, T. Namimatsu, T. Osumi, et al., "Molecular typing and antimicrobial resistance of Salmonella enterica subspecies enterica serovar Choleraesuis isolates from diseased pigs in Japan," Comparative Immunology, Microbiology and Infectious Diseases, vol. 33, no. 2, pp. 109-119, 2010.

[69] T. Asai, K. Murakami, M. Ozawa, R. Koike, and H. Ishikawa, "Relationships between multidrug-resistant Salmonella enterica serovar Schwarzengrund and both broiler chickens and retail chicken meats in Japan," Japanese Journal of Infectious Diseases, vol. 62, no. 3, pp. 198-200, 2009.

[70] T. Asai, M. Itagaki, Y. Shiroki, et al., "Antimicrobial resistance types and genes in Salmonella enterica Infantis isolates from retail raw chicken meat and broiler chickens on farms," Journal of Food Protection, vol. 69, no. 1, pp. 214-216, 2006.

[71] T. Asai, K. Ishihara, K. Harada, et al., "Long-term prevalence of antimicrobial-resistant Salmonella enterica subspecies enterica serovar infantis in the broiler chicken industry in Japan," Microbiology and Immunology, vol. 51, no. 1, pp. 111-115, 2007.

[72] K. Harada, M. Ozawa, K. Ishihara, R. Koike, T. Asai, and H. Ishikawa, "Prevalence of antimicrobial resistance among serotypes of Campylobacter jejuni isolates from cattle and poultry in Japan," Microbiology and Immunology, vol. 53, no. 2, pp. 107-111, 2009.

[73] K. Ishihara, S. Yano, M. Nishimura, et al., "The dynamics of antimicrobial-resistant Campylobacter jejuni on Japanese broiler farms," Journal of Veterinary Medical Science, vol. 68, no. 5, pp. 515-518, 2006.

[74] B. E. Langlois, K. A. Dawson, I. Leak, and D. K. Aaron, "Effect of age and housing location on antibiotic resistance of fecal coliforms from pigs in a non-antibiotic-exposed herd," Applied and Environmental Microbiology, vol. 54, no. 6, pp. 1341-1344, 1988.

[75] K. Sato, P. C. Bartlett, and M. A. Saeed, "Antimicrobial susceptibility of Escherichia coli isolates from dairy farms using organic versus conventional production methods," Journal of the American Veterinary Medical Association, vol. 226, no. 4, pp. 589-594, 2005. 
[76] K. A. Ray, L. D. Warnick, R. M. Mitchell, et al., "Antimicrobial susceptibility of Salmonella from organic and conventional dairy farms," Journal of Dairy Science, vol. 89, no. 6, pp. 2038 2050, 2006.

[77] C. E. Siemon, P. B. Bahnson, and W. A. Gebreyes, "Comparative investigation of prevalence and antimicrobial resistance of Salmonella between pasture and conventionally reared poultry," Avian Diseases, vol. 51, no. 1, pp. 112-117, 2007.

[78] A. G. Mathew, A. M. Saxton, W. G. Upchurch, and S. E. Chattin, "Multiple antibiotic resistance patterns of Escherichia coli isolates from swine farms," Applied and Environmental Microbiology, vol. 65, no. 6, pp. 2770-2772, 1999.

[79] Y. Kumai, Y. Suzuki, Y. Tanaka, et al., "Characterization of multidrug-resistance phenotypes and genotypes of Escherichia coli strains isolated from swine from an abattoir in Osaka, Japan," Epidemiology and Infection, vol. 133, no. 1, pp. 59-70, 2005.

[80] N. F. Florea and C. H. Nightingale, "Review of the pharmacodynamics of antibiotic use in animal food production," Diagnostic Microbiology and Infectious Disease, vol. 49, no. 2, pp. 105-108, 2004.

[81] M. H. Moro, G. W. Beran, L. J. Hoffman, and R. W. Griffith, "Effects of cold stress on the antimicrobial drug resistance of Escherichia coli of the intestinal flora of swine," Letters in Applied Microbiology, vol. 27, pp. 251-254, 1988.

[82] M. H. Moro, G. W. Beran, R. W. Griffith, and L. J. Hoffman, "Effects of heat stress on the antimicrobial drug resistance of Escherichia coli of the intestinal flora of swine," Journal of Applied Microbiology, vol. 88, no. 5, pp. 836-844, 2000.

[83] H. Sørum and M. Sunde, "Resistance to antibiotics in the normal flora of animals," Veterinary Research, vol. 32, pp. 227241, 2001.

[84] B. R. Levin, V. Perrot, and N. Walker, "Compensatory mutations, antibiotic resistance and the population genetics of adaptive evolution in bacteria," Genetics, vol. 154, no. 3, pp. 985-997, 2000.

[85] V. I. Enne, A. A. Delsol, G. R. Davis, S. L. Hayward, J. M. Roe, and P. M. Bennett, "Assessment of the fitness impacts on Escherichia coli of acquisition of antibiotic resistance genes encoded by different types of genetic element," Journal of Antimicrobial Chemotherapy, vol. 56, no. 3, pp. 544-551, 2005.

[86] A. R. Khachatryan, D. D. Hancock, T. E. Besser, and D. R. Call, "Antimicrobial drug resistance genes do not convey a secondary fitness advantage to calf-adapted Escherichia coli," Applied and Environmental Microbiology, vol. 72, no. 1, pp. 443-448, 2006. 

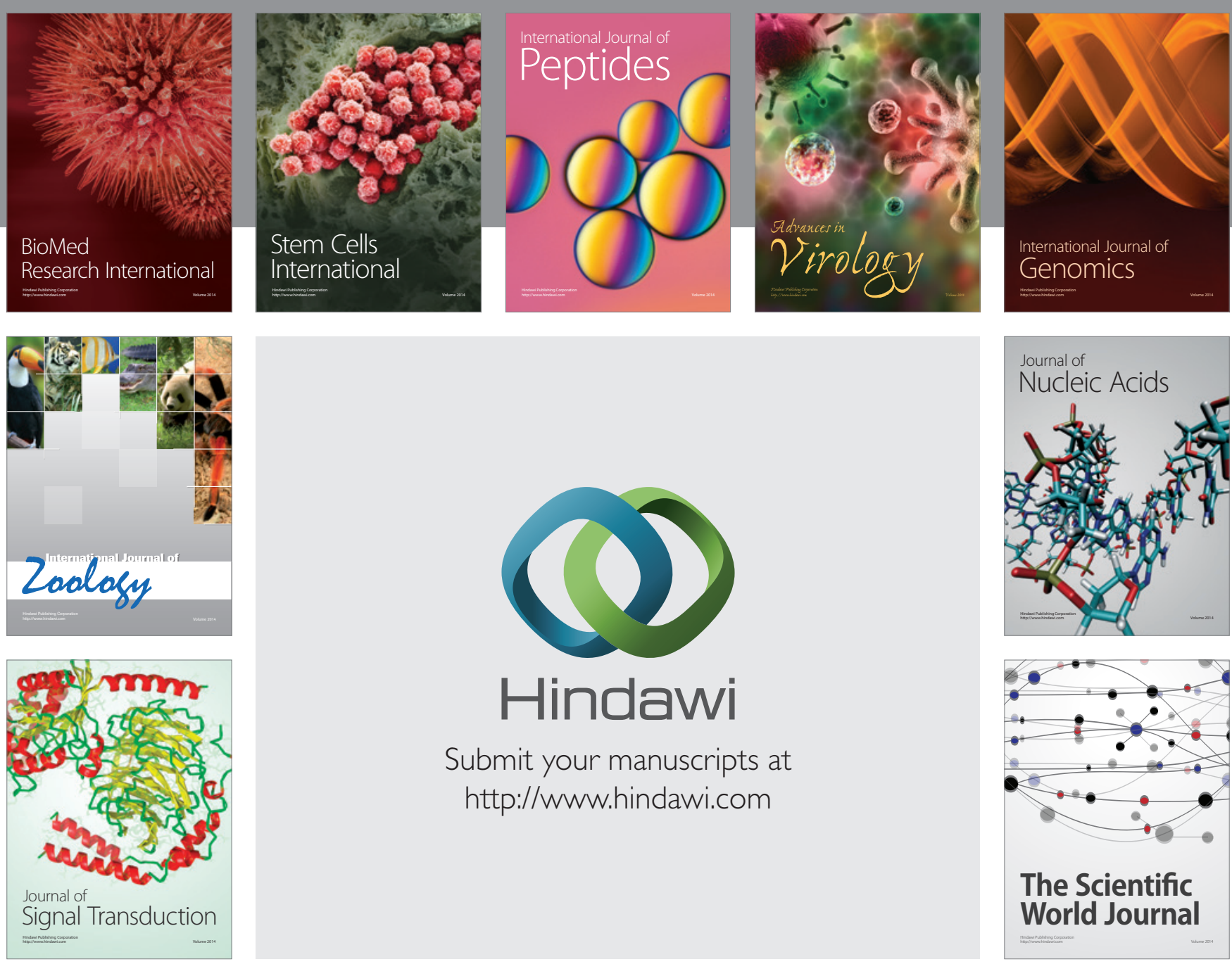

Submit your manuscripts at

http://www.hindawi.com
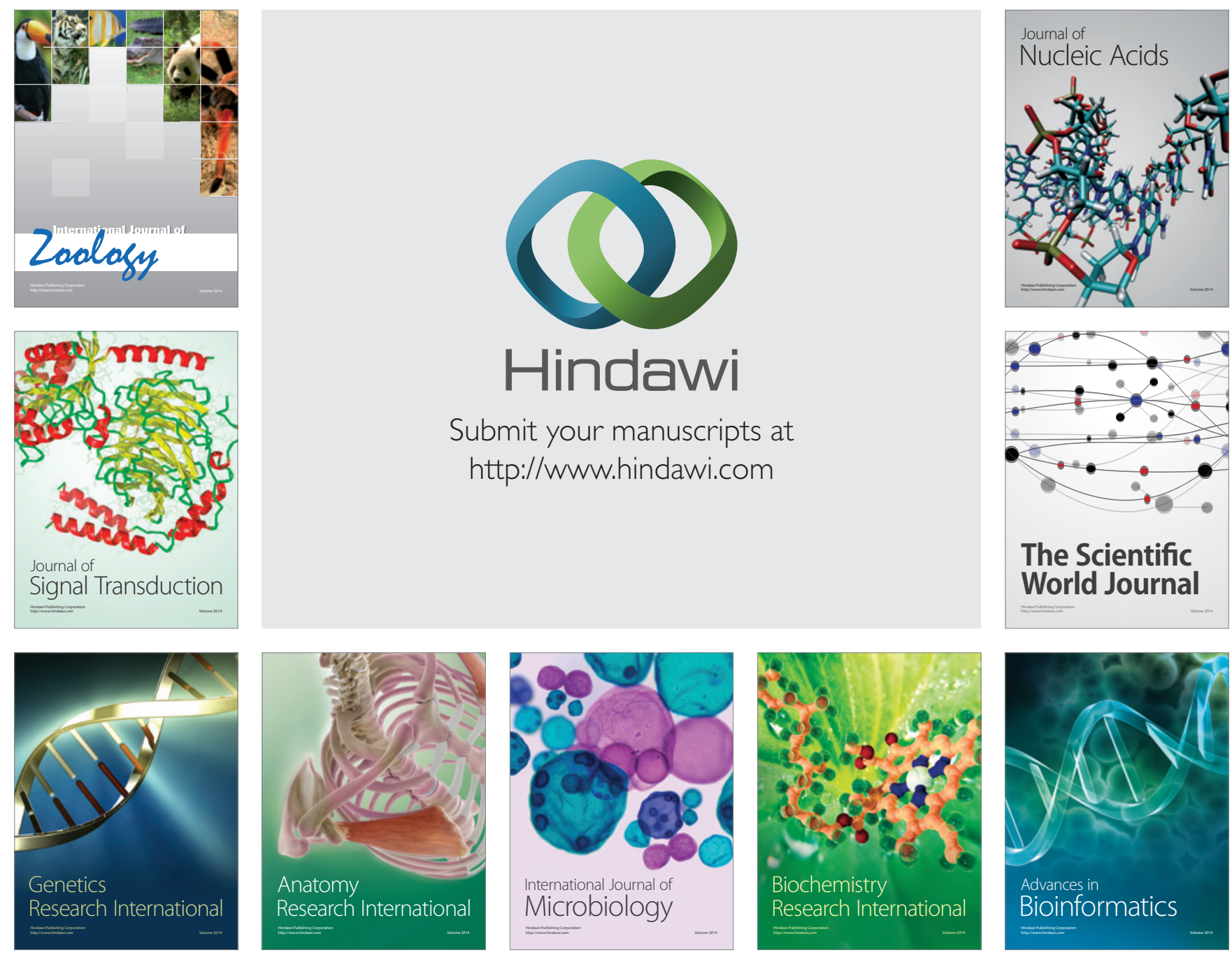

The Scientific World Journal
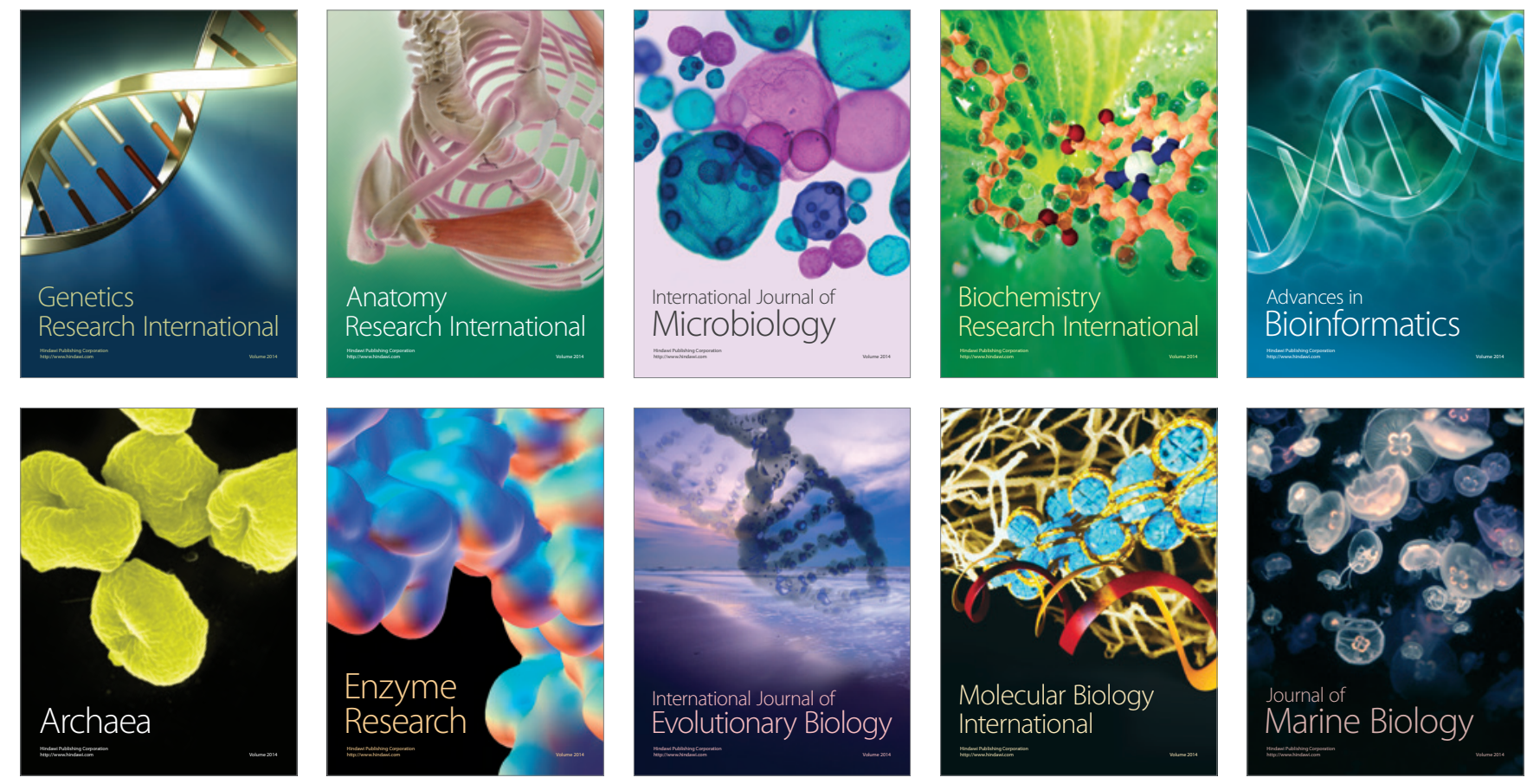